\title{
Retinal axonal degeneration in Niemann-Pick type C disease
}

\author{
Joachim Havla ${ }^{1}$ - Marlene Moser ${ }^{2}$ - Clara Sztatecsny ${ }^{2}$ - Amelie S. Lotz-Havla ${ }^{3}$ Esther M. Maier ${ }^{3}$ - Baccara Hizli ${ }^{2}$. \\ Regina Schinner ${ }^{5} \cdot$ Tania Kümpfel $^{1} \cdot$ Michael Strupp $^{2} \cdot$ Tatiana Bremova-Ertl $^{2,4} \cdot$ Susanne A. Schneider ${ }^{2}$
}

Received: 8 February 2020 / Revised: 13 March 2020 / Accepted: 14 March 2020 / Published online: 28 March 2020

(c) The Author(s) 2020

\begin{abstract}
Objective Niemann-Pick disease type C1 (NPC1) is a rare autosomal-recessive lysosomal storage disorder presenting with a broad clinical spectrum ranging from a severe infantile-onset neurovisceral disorder to late-onset neurodegenerative disease. Optical coherence tomography (OCT) is established to detect retinal degeneration in vivo. We examined NPC1-patients (NPC1-P), clinically asymptomatic NPC1-mutation carriers (NPC1-MC), and healthy controls (HC) to (1) identify retinal degeneration in NPC1-disease and (2) to investigate possible subclinical retinal degeneration in NPC1-MC.

Methods Fourteen NPC1-P, 17 NPC1-MC, and 31 age-matched HC were examined using spectral-domain OCT. Neurological examinations, clinical scales [modified Disability Rating Scale (mDRS); Scale for the Rating and Assessment of Ataxia (SARA); Spinocerebellar Ataxia Functional Index (SCAFI)], and video-oculography (VOG) were correlated with OCT data. Results Macular retinal nerve fiber layer and volumes of combined ganglion cell and inner plexiform layer were significantly lower in NPC1-P compared to HC [mRNFL $(\mu \mathrm{m}): 0.13 \pm 0.01$ vs. $0.14 \pm 0.02 ; p=0.01 ; \mathrm{GCIPL}\left(\mathrm{mm}^{3}\right): 0.60 \pm 0.05$ vs. $0.62 \pm 0.04 ; p=0.04]$. No significant differences were found in NPC1-MC in comparison to HC. In NPC1-P, the amplitude of upward vertical saccades showed positive associations with peripapillary RNFL $(\rho=0.645 ; p<0.05)$, and thinned GCIP $(\rho=0.609 ; p<0.05)$, but not in NPC1-MC. In NPC1-P correlations between combined outer plexiform layer and outer nuclear layer (OPONL) with mDRS $(r=-0.617 ; p<0.05)$ and GCIP with SARA $(r=-0.622 ; p<0.05)$ were observed. Furthermore, in NPC1-MC, motor scores were negatively associated with pRNFL $(\rho=-0.677 ; p<0.01)$.

Conclusions Using OCT, we showed retinal degeneration in NPC1-P and significant correlation between retinal neuroaxonal degeneration with clinical measurements. We observed a non-significant trend of retinal degeneration in NPC1-MC correlating with subclinical motor abnormalities. Based on these preliminary data, OCT may be an important marker of neurodegeneration in NPC1-disease after onset of clinical symptoms.
\end{abstract}

Keywords Niemann-Pick type C $\cdot$ Heterozygosity $\cdot$ Clinical biomarker $\cdot$ Optical coherence tomography $\cdot$ Retinal neuroaxonal degeneration

\section{Introduction}

Niemann-Pick disease type C (NPC) is an autosomal recessively inherited neurovisceral lysosomal disorder caused by mutations in the NPC1 or NPC2 gene [1,2]. The clinical phenotype ranges from an infancy-onset progressive, fatal

Tatiana Bremova-Ertl and Susanne A. Schneider have contributed equally to this work.

Joachim Havla

joachim.havla@med.lmu.de

Susanne A. Schneider

susanne.schneider@med.uni-muenchen.de

Extended author information available on the last page of the article disorder to an adult-onset, chronic neurodegenerative disease with heterogeneous clinical symptoms such as cognitive impairment, cerebellar symptoms, dystonia, vertical supranuclear saccade and gaze palsy, psychiatric disorders, and, less frequently, epilepsy [3]. Optic nerve pallor and perimacular gray discoloration are observed ophthalmologically, as well as histologically [4]. However, markers reflecting disease progression in NPC are not well established. Pathophysiologically, NPC is characterized by abnormalities of intracellular transport of endocytosed cholesterol and further lipids with their sequestration in lysosomes and late endosomes $[5,6]$. Notably, dysregulation of brain cholesterol homeostasis is also present in some of the common neurodegenerative central nerve system (CNS) disorders 
such as Alzheimer`s disease (AD) and Parkinson's disease (PD) [7-9]. In addition, NPC and AD share common pathophysiological mechanisms such as neurofibrillary tangle formation, increased amyloidogenic amyloid precursor protein (APP), early development of endosome abnormalities, and neuronal death [10-13]. Optical coherence tomography (OCT) is a non-invasive, cost-effective, and widely used imaging technique of the retinal layers introduced in the last few years as a potential marker of neurodegeneration in various neuroinflammatory and neurodegenerative disorders [14, 15]. Furthermore, in metabolic diseases such as Gaucher's disease (GD), which shows pathophysiological similarities to NPC [16], retinal neuroaxonal degeneration can be measured with OCT [17]. To our knowledge, OCT has not been used to study possible neurodegeneration in NPC yet.

In this study, we examined NPC1-P, clinically healthy NPC1-MC, and HC using OCT to (i) identify retinal degeneration in NPC disease using a non-invasive OCT technique and (ii) to investigate for possible subclinical retinal atrophy in NPC1-mutation carriers (MC). We aimed to show a correlation between OCT examinations and the clinically recorded scores to establish neuroaxonal degeneration as a disease-monitoring tool in NPC.

\section{Materials and methods}

\section{Study population}

Twelve NPC1-P with biallelic NPC1 gene mutations and two patients with one identifiable mutation, a classical or variant filipin test in cultured fibroblasts and a typical NPC phenotype (vertical supranuclear saccade palsy, cerebellar ataxia, dysarthria, cognitive impairment, dystonia; mean age 24 [range 9-38]; 8 male) were recruited from the university hospital specialized unit (Table 1). Mean duration of the disease was $14 \pm 6.5$ (SD) years. Seventeen of their asymptomatic first-degree family members, all confirmed heterozygous NPC1-MC (i.e., carrying one muted allele; mean age 50 [range 21-65]; 8 males) were included (Table 2). No neurological comorbidity was diagnosed based on a detailed examination by experts in movement disorders (TBE and SAS). The motor examinations were not evaluated blinded. Two $\mathrm{HC}$ groups age-matched for patients and carriers were also enrolled (14 HC for NPC1-P: mean age 27 [range 12-38] 7 males; $17 \mathrm{HC}$ for NPC1-MC: mean age 51 [range 21-66]; 9 male). In the NPC1-P group, only 26 of the 28 eyes could be examined. Two patients discontinued the examination incompletely after examination of the first eye. Eight out of fourteen patients suffered from an organic psychiatric disorder due to NPC disease and took antipsychotic drugs. To our knowledge, there is no evidence of an effect of psychiatric medication on the OCT data shown here. This also applies to the anticonvulsive drugs. Subjects, and single eyes, respectively, with concomitant potentially OCT-confounding diseases (glaucoma, diabetes mellitus, retinal surgery, retinal disease, and ametropia $>6$ diopters) were also excluded. Evaluation criteria for this study were retinal thickness/volume and visual disability measured by high and low contrast visual acuity (VA). Patients and mutation carriers underwent neurological examination and demographic information was obtained as summarized in Tables 1 and 2. Other causes that could explain motor anomalies were excluded by anamnesis and examinations as needed. Written informed consent was obtained from all patients participating in the study. The study was performed in accordance with the Helsinki II Declaration and approved by the ethics committee of the Ludwig-Maximilians-University, Munich, Medical Faculty (part of project no 280-16). All participants (or their legal representatives) gave written informed consent.

\section{Optical coherence tomography (OCT)}

OCT examination was performed using an SD-OCT (Spectralis, Heidelberg Engineering, Heidelberg, Germany) with automatic real-time (ART) function for image averaging. We acquired peripapillary retinal nerve fiber layer thickness (pRNFL), macular RNFL (mRNFL), and volumes of combined ganglion cell and inner plexiform layer (GCIP), and combined outer plexiform layer and outer nuclear layer (OPONL). All macular layers were calculated as a $3 \mathrm{~mm}$ diameter cylinder around the fovea from a macular volume scan $\left(20^{\circ} \times 20^{\circ}, 25\right.$ vertical B-scans, ART $\left.\leq 49\right)$. The peripapillary RNFL (pRNFL) was measured with activated eye tracker using $3.4 \mathrm{~mm}$ ring scans around the optic nerve $\left(12^{\circ}\right.$, 1536 A-scans, ART $\leq 100)$. Segmentation of all layers was performed semi-automatically using software provided by the OCT manufacturer (Eye Explorer 1.9.10.0 with viewing module 6.3.4.0, Heidelberg Engineering, Heidelberg, Germany). One experienced rater ( $\mathrm{JH})$, blinded for the diagnosis, carefully checked all scans for sufficient quality and segmentation errors and corrected if necessary. OCT data in this study are reported and analyzed according to the APOSTEL and OSCAR-IB recommendations [18, 19]. The data were correlated with VOG measures and clinical scores.

\section{Video-oculography (VOG)}

Since patients with NPC demonstrate characteristic ocular motor deficits, including, but not limited to vertical supranuclear saccade palsy (VSSP), video-oculography (VOG) was performed in both NPC1-P and NPC1-MC, using a videobased eye-tracker system (EyeSeeCam ${ }^{\circledR}$, Munich, Germany) as previously described [20,21]. Briefly, reflexive saccades 


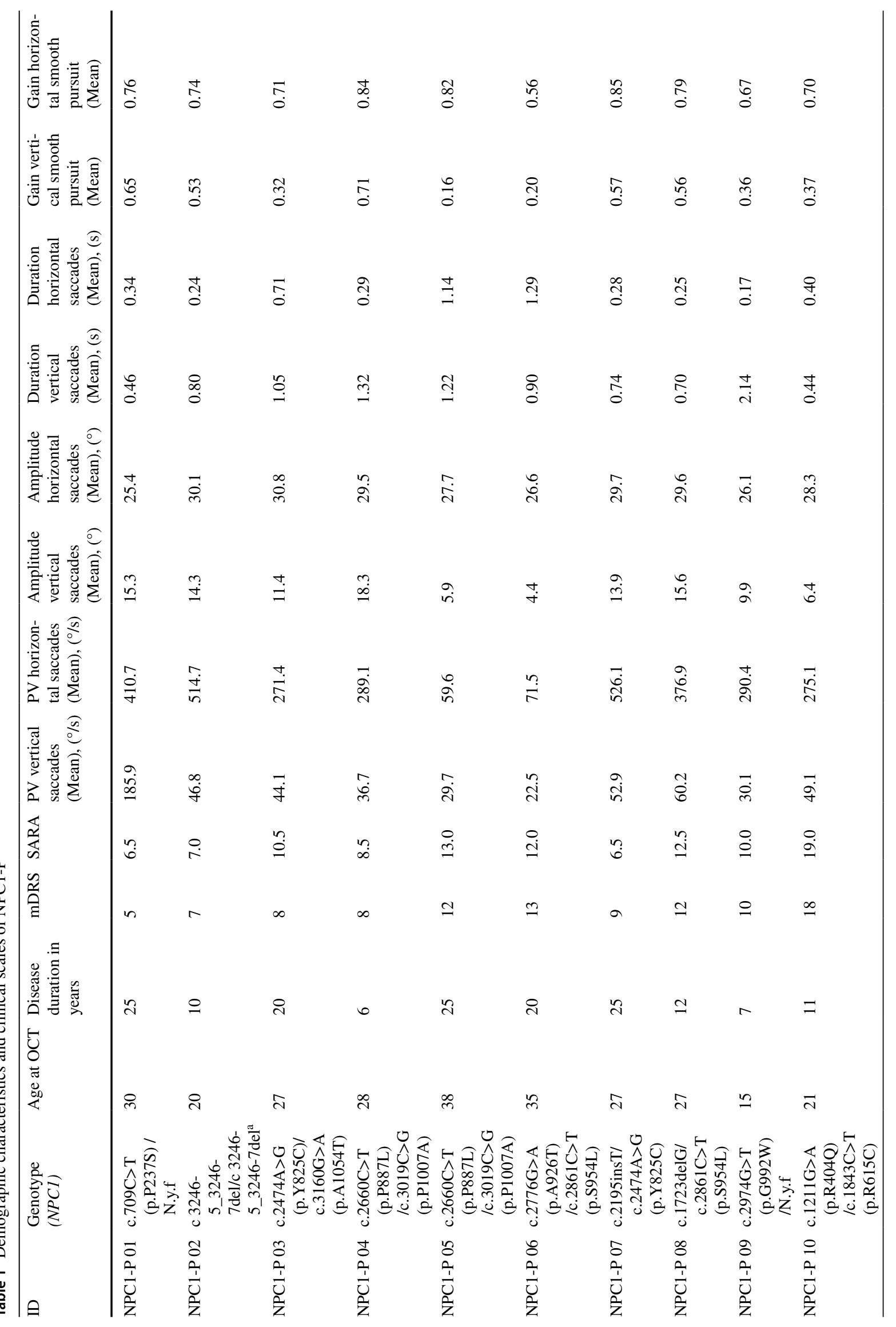




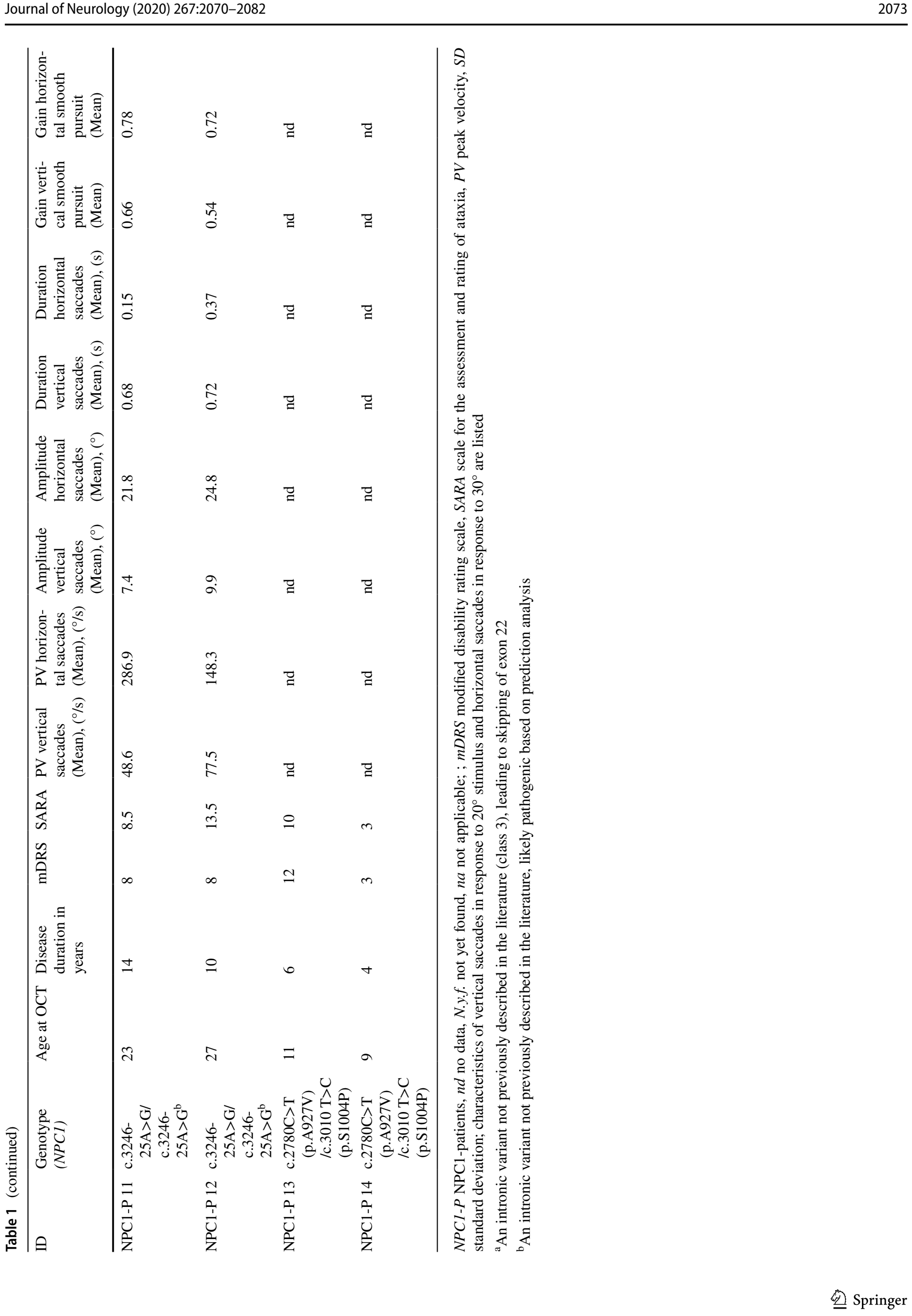




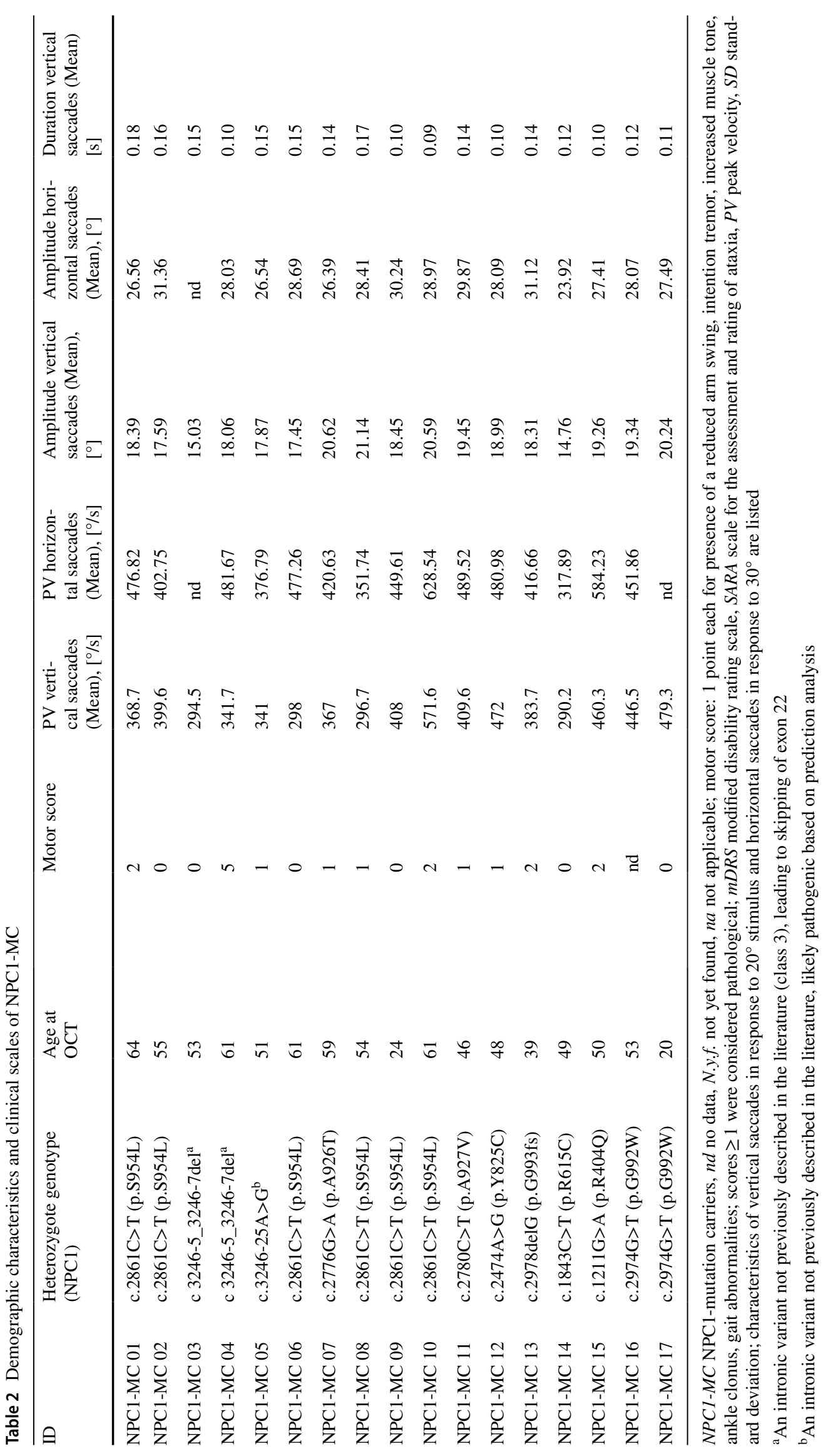


that reflect brainstem function and smooth pursuit for cerebellar function were assessed.

\section{Clinical assessment}

To assess the overall neurologic status in NPC disease, the modified Disability Rating Scale (mDRS) by Pineda et al. [22] was applied; the mDRS is a four-domain scale (ambulation, manipulation, language, and swallowing) in an extended form [23], which also includes seizures and ocular movements, that assesses the severity of the disease and monitors the effect of treatment. All patients were examined by the same experienced neurologist (TBE) to reduce inter-rater variability. Cerebellar function was evaluated by administrating the Scale for the Rating and Assessment of Ataxia (SARA) [24] an eight-item clinical rating scale (gait, stance, sitting, speech, fine motor function, and taxis; range $0-40$, with 0 being the best neurological status and 40 the worst). Moreover, NPC1-P were assessed by the Spinocerebellar Ataxia Functional Index (SCAFI), comprising the 8 -m-Walking-Test (8MW), performed by having patients walking twice as quickly as possible from one line to another excluding turning, 9-Hole-Peg-Test (9HPT), and the number of "PATA" repetitions over $10 \mathrm{~s}$ (PATA) [25]. NPC1-MC were clinically assessed by an experienced neurologist in the field of movement disorders (SAS) with a particular focus on signs and symptoms of NPC disease: 1 point each was given for presence of a reduced arm swing, intention tremor, increased muscle tone, ankle clonus, and/or gait abnormalities resulting in a final motor score [26]. Scores $\geq 1$ were considered pathological.

\section{Statistical analysis}

The groups of patients and carriers were separately compared to a group of age-matched healthy controls. Data are presented as mean and standard deviation for continuous parameters and frequency and proportion for categorical variables. To compare OCT measures between subpopulations, and to consider within-patient inter-eye correlation, we used generalized estimation equation models (GEEs), in which the correlation matrix parameter was set to 'exchangeable'. In these models, OCT measures were the dependent variables, while patient's disease status was the (main) independent variable. Furthermore, in adjusted GEE analyses, the additional independent variables gender and age were added. To evaluate the strength of relationship between relevant OCT measures that were significantly decreased in homozygotes and clinical variables, we calculated the Spearmen's correlation coefficients. Due to the fact that the correlations were not random but based on patient findings and were, therefore, limited in number, we did not perform a post-hoc correction. Statistical significance was achieved at $p<0.05$. Data were analyzed with SAS version 9.3 (SAS institute, Cary, NC, USA) by a statistician (RS). Clinical correlations were performed in SPSS version 25.0.0 (IBM, Armonk, NY; done by TBE).

\section{Results}

\section{Cross-sectional group differences}

For statistical analysis, we evaluated 26 eyes of 14 NPC1-P and 34 eyes of 17 NPC1-MC. These eyes were compared with 28 eyes of 14 age- and sex-matched HC. NPC1-P had a significantly lower $\mathrm{mRNFL}$ (mean $\pm \mathrm{SD}, 0.13 \pm 0.01 \mathrm{~mm}^{3}$ ) and GCIPL $\left(0.60 \pm 0.05 \mathrm{~mm}^{3}\right)$ compared to HC (mRNFL $\left.0.14 \pm 0.02 \mathrm{~mm}^{3} ; p=0.01 ; \mathrm{GCIP} 0.62 \pm 0.04 \mathrm{~mm}^{3} ; p=0.04\right)$ (Fig. 1). pRNFL showed a trend, but the difference was non-significant $(98.12 \pm 11.46 \mu \mathrm{m}$ vs. $104.61 \pm 8.39 \mu \mathrm{m}$; $p=0.06)$. No significant differences were observed for PMB, TMV, and OPONL. Furthermore, there were no significant differences between NPC1-MC and HC for all studied parameters (summarized in Table 3). An orienting comparison of visual acuity data showed a reduced Snellen Visual Acuity Equivalent (SVAE) and a reduced number of recognized letters (100\%/2.5\% Low-Contrast Sloan Letter Chart Testing ( $2 \mathrm{~m}$ ), see Table 3 ) in the group of NPC1-P. A statistical analysis was not performed for unequally distributed missing VA values.

\section{Correlation OCT with clinical scores}

In NPC1-P, mean mDRS score correlated only with mean OPONL $(\rho=-0.617, p<0.05)$. Mean SARA score was negatively related to GCIP $(\rho=-0.622, p<0.05)$ (Fig. 2a, b). In NPC1-MC, motor scores (Table 1) were negatively associated with mean pRNFL (Average: $\rho=-0.719 ; p<0.01$ ) (Fig. 2c). No further correlations with clinical scores were seen.

\section{Correlation OCT with saccades and smooth pursuit}

Amplitude of upward vertical saccades to $20^{\circ}$ stimulus in NPC1-P showed positive associations with averaged pRNFL $(\rho=0.645, p<0.05)$ and averaged GCIP $(\rho=0.609$, $p<0.05$ ) (Table 1, Fig. 3a, b). Mean peak velocity of horizontal saccades to $30^{\circ}$ stimulus correlated with averaged $\operatorname{pRNLF}(\rho=0.650, p<0.05)$ and averaged GCIP $(\rho=0.750$, $p<0.01$ ) (Table 1, Fig. 3c, d). Mean duration of horizontal saccades correlated negatively with pRNLF $(\rho=-0.727$, $p<0.01$ ) (Table 1, Fig. 3e). Averaged GCIP tracked with vertical smooth pursuit gain $(\rho=0.622, p<0.05)$ (Table 1 , Fig. 3f). In NPC1-MC, there were no significant associations 

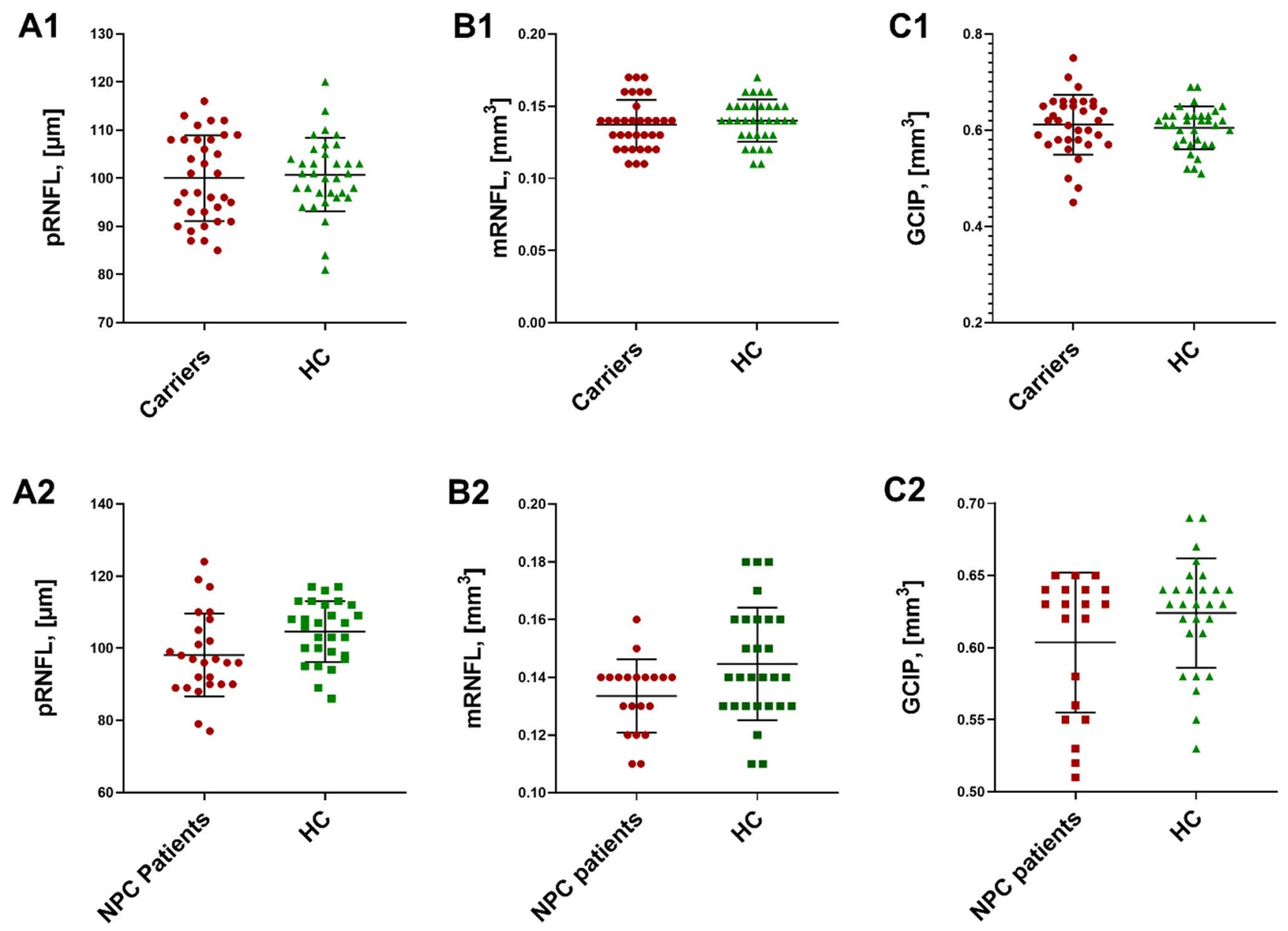

Fig. 1 OCT results of NPC1-P, NPC1-MC, and HCs. NPC1-P: NPC1-Patients and NPC1-MC: NPC1-Mutation Carriers; Box plots of cross-sectional OCT data for NPC1-MC vs. HC (A1, B1, C1) and

between the retinal and video-ocular motor measures (data not shown).

\section{Discussion}

In this study, we examined NPC1-P, clinically asymptomatic NPC1-MC, and HC using OCT to identify retinal degeneration and to evaluate the potential eligibility of OCT measures as biomarkers of neurodegeneration and disease progress. OCT proved to be a precise and reproducible method [27] for non-invasive visualization and quantification of retinal layers, and plays a crucial role in analyzing retinal changes in various neurodegenerative [15] and neuroinflammatory diseases [28-30]. Due to its anatomical, embryological, and physiological similarities with the brain, the retina offers a unique and easily accessible "window" to study correlates and consequences of subclinical pathology in the brain [31].
NPC1-P vs. HC (A2, B2, C2). A: peripapillary retinal nerve fiber layer (pRNFL), B: macular retinal nerve fiber layer (mRNFL) and C: ganglion cell and inner plexiform layer (GCIP)

The major findings of this study are as follows: first, retinal neuronal and axonal degeneration in NPC1-P was significantly related to clinical disease scores. Second, for asymptomatic heterozygous NPC1-MC, there was no significant retinal degeneration. However, the extent of retinal neurodegeneration was significantly related to subclinical abnormalities in carriers.

In NPC1-P, we found a significantly lower thickness of mRNFL as well as a non-significant trend of reduced pRNFL compared to controls. The reduction of $\mathrm{pRNFL}$ has been described as a retinal marker of a possible dementia development, including AD [32], and may serve as a marker of disease progression in $\mathrm{PD}, \mathrm{AD}$, and frontotemporal dementia [33-35]. Our data are in line with those findings; however, only the reduction of mRNFL but not of the pRNFL reached the level of significance. The non-congruent effect of pRNFL and mRNFL might be due to the small volume of the RNFL measurement or a consequence of the small sample size. Our findings on reduced thickness of the 


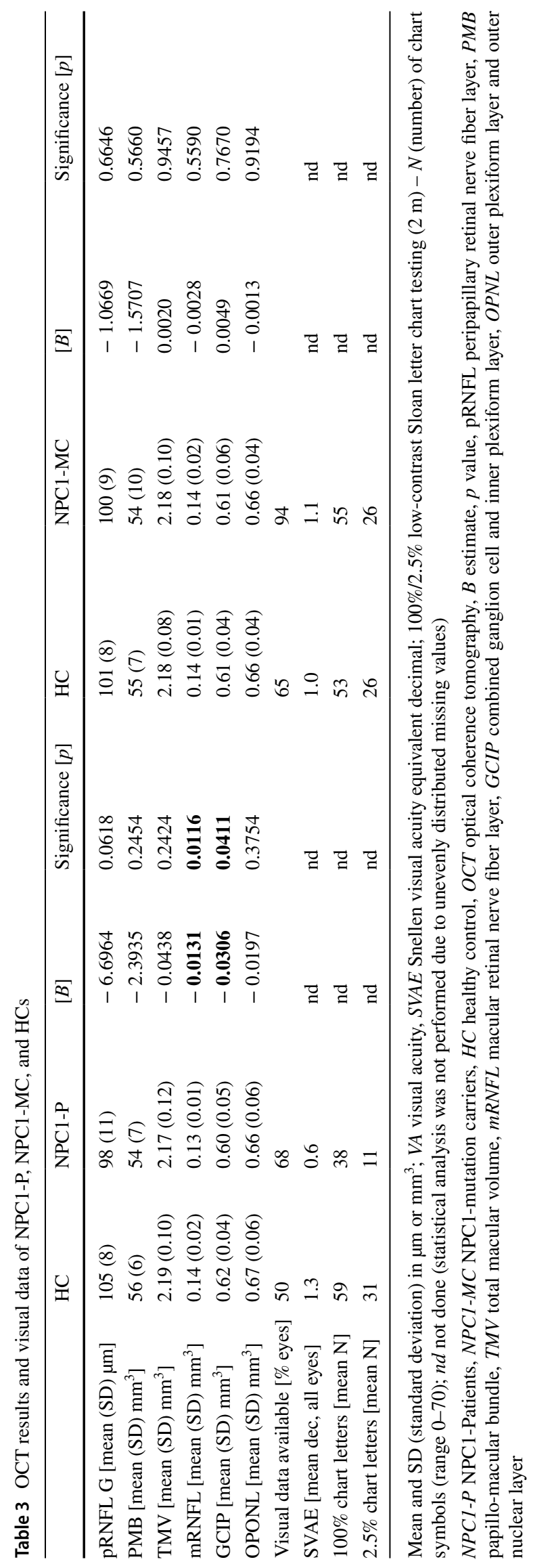



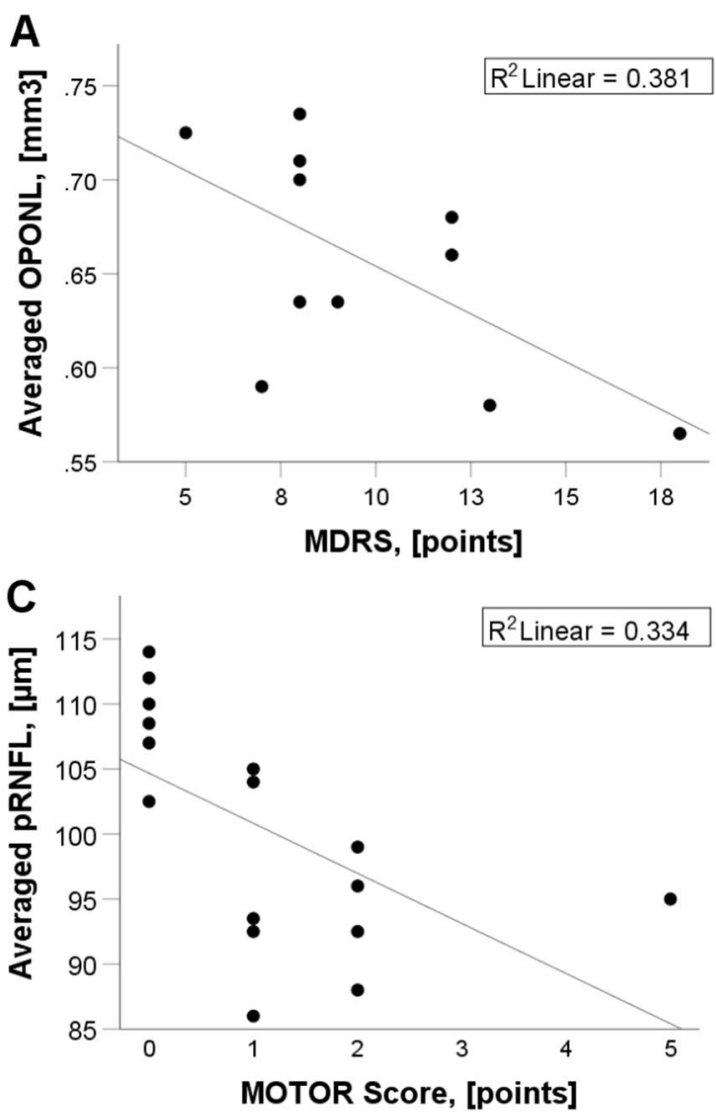

Fig. 2 Relationships between OCT measures and disease severity scales in NPC1-P (a, b) and in NPC1-MC (c). mDRS modified disability rating scale, SARA scale for the assessment and rating of ataxia. Motor score: one point each for presence of a reduced arm swing, intention tremor, increased muscle tone, ankle clonus, and gait

retinal nerve fiber layer strengthen the hypothesis of a common pathomechanisms in NPC and other neurodegenerative diseases. pRNFL atrophy has also been reported in $\mathrm{AD}, \mathrm{PD}$, and other neurodegenerative diseases including rare diseases such as Leber's hereditary optic neuropathy (LHON), OPA1related dominant optic nerve atrophy (DOA) [36], Wilson`s disease [15], Friedreich`s ataxia [37], and spinocerebellar ataxias [38]. Histologic and OCT studies in AD and PD showed a significant loss of retinal ganglion cells [39, 40]. In line with these data, we found a significantly lower thickness of GCIP in NPC1-P compared to HC. However, the pathophysiology leading to retinal degeneration in NPC remains unclear. GCIP atrophy might be explained by the predominant mitochondrial dysfunction and oxidative stress [41]. In line with this hypothesis, functional studies in NPC have shown an increase in autophagy markers in the ganglion cell layer and the upregulation of proteins that mediate cellular cholesterol release in the retina [42]. Finally, inflammation has been suggested to play a key role in the pathogenesis of NPC [43]. In analogy to the known GCIP degeneration in

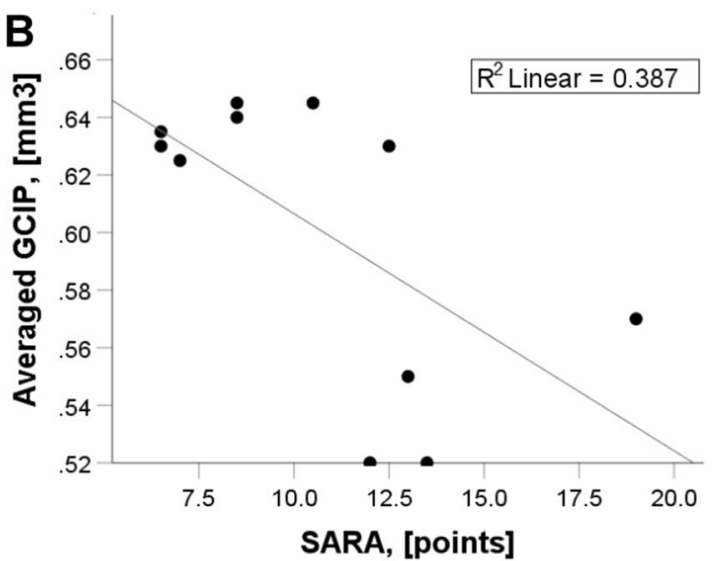

abnormalities. Scores $\geq 1$ were considered pathological. $\mathrm{R}^{2}$ represents a goodness-of-fit measure for linear regression model. $p R N F L$ peripapillary retinal nerve fiber layer thickness, GCIP volumes of combined ganglion cell and inner plexiform layer, $O P N L$ combined outer plexiform layer and outer nuclear layer

multiple sclerosis [44], one might speculate that the atrophy of the ganglion cells in NPC1 could be at least be partly explained by inflammatory processes.

Recently, various subclinical abnormalities in asymptomatic heterozygote NPC1-mutation carriers have been described including hepatosplenomegaly, increased cholestantriol, and plasma chitotriosidase and features of early neurodegenerative disease, e.g., impaired cognitive function, hyposmia, features suggestive of REM sleep behavior disorder, and decreased glucose metabolic rates on PET imaging [26]. We found no retinal neuronal and axonal degeneration in our NPC1-MC, but we did observe a nonsignificant trend towards lower mRNFL as seen in NPC1-P. Notably, peripapillary retinal nerve fiber layer thickness in NPC1-MC correlated with suspicious motor scale scores. These preliminary observations are of special interest, as they are in line with OCT findings in a related metabolic disorder, Gaucher's disease (GD), in which heterozygous mutations in the GBA gene are the most frequent genetic risk factor for developing late-onset Parkinson's disease 

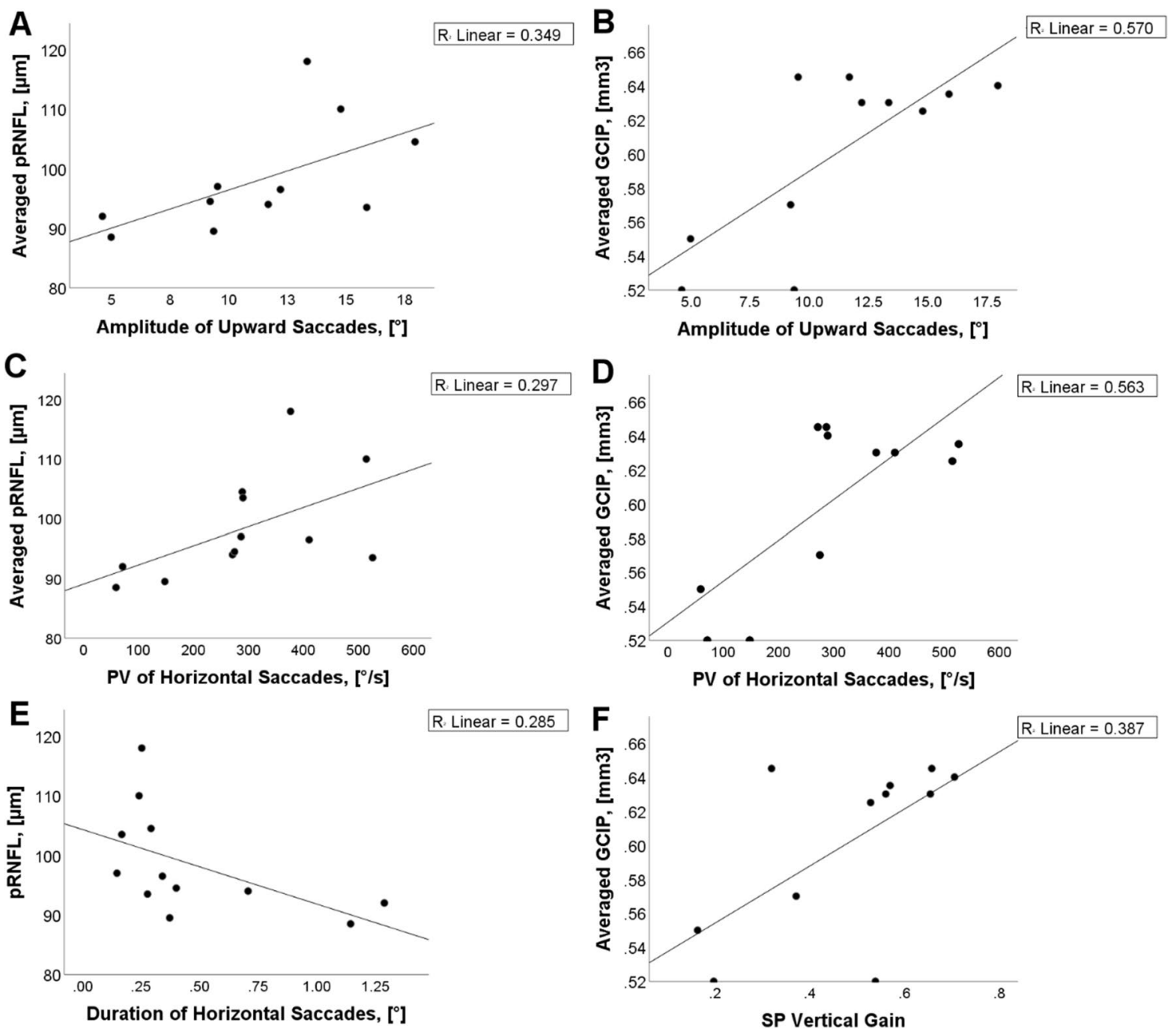

Fig. 3 Relationships between OCT measures and video-oculography data. In a and $\mathbf{b}$ correlation with upward vertical saccades to $20^{\circ}$ stimulus, in $\mathbf{c}$ and $\mathbf{d}$ with mean peak velocity (PV), in $\mathbf{e}$ with the duration of horizontal saccades, and in $\mathbf{f}$ with vertical smooth pursuit (SP)

[45]. In GD ganglion cell layer atrophy was found in GD patients but also in asymptomatic mutation carriers [17]. Indeed, animal studies in NPC1-mutant mice demonstrated preclinical retinal degeneration and lipofuscin accumulation in the pigment epithelium and ganglion cells, electrodense inclusions in various cell types, photoreceptor defects, and hyperactivity of glial cells $[42,46]$, as well as optic nerve pallor and per macular grey discoloration [47]. Given the pathomechanistic similarities between NPC and GD, we encourage additional work in NPC heterozygotes to shed further light on potential similar risks.

As we did observe a correlation between OCT values and subtle neurologic findings in clinical tests and scores in patients and in heterozygous mutation carriers, we were able to evaluate the potential eligibility of OCT measures as biomarkers of neurodegeneration and disease progress. In NPC1-P, a clear negative correlation between a decrease in

gain are shown. $p R N F L$ peripapillary retinal nerve fiber layer thickness, GCIP volumes of combined ganglion cell and inner plexiform layer, $O P O N L$ combined outer plexiform layer and outer nuclear layer

GCIP as a sign of retinal neurodegeneration and an increase in cerebellar ataxia as a sign of severity of the NPC1-phenotype could be shown. In addition, the extent of the decrease in OPONL correlated with the severity of motor impairment (mean mDRS). Furthermore, we correlated saccadic and smooth pursuit measures with retinal characteristics. The amplitude of upward vertical saccades to $20^{\circ}$ stimulus and the mean peak velocity of horizontal saccades to $30^{\circ}$ stimulus in NPC1-patients showed positive associations with averaged pRNFL and averaged GCIP. In NPC1-MC, there were no significant associations between the retinal and ocular motor measures. In line with the VOG study of a large NPC cohort [20], horizontal saccades peak velocity and duration are related to the disease characteristics. This is due to the functional impairment of burst neurons in rostral interstitial nucleus of the medial longitudinal fascicle (riMLF) in the rostral mesencephalon. Based on the correlations shown, 
it might be considered to monitor disease progression in NPC1-P after clinical manifestation by measuring retinal axonal and neuronal degeneration.

The study has several limitations. Due to the rarity of this metabolic disease, the sample size is small and confirmation by an independent group is encouraged. We took a cross-sectional approach, but future longitudinal studies may help to validate the described retinal pattern. In addition, NPC1-P with the presumably most pronounced retinal pathology could not be included in the study. Due to their severe clinical affection such as pronounced cerebellar ataxia and dementia, they had difficulties to undergo OCT.

In summary, by retinal imaging using the OCT technique, we provided additional and complementary diagnostic information in symptomatic NPC1-P. Since OCT is a non-invasive, safe, and highly precise diagnostic tool, we expect an increasing impact of OCT in the diagnostic workup of NPC, particularly of adult-onset NPC1, in which the clinical symptoms are often mild and non-specific. Furthermore, longitudinal OCT analyses will help to understand the disease specificity of our findings and the opportunities to integrate this technique into the daily clinical practice. Finally, on the basis of our findings, the role of OCT to monitor disease progression and treatment response in NPC1 has to be evaluated.

Acknowledgements Open Access funding provided by Projekt DEAL. We would like to thank Angelika Bamberger and Luise Böhm for their excellent technical support. We would also like to thank Dr Kathrin Hartmann for useful discussion when preparing the study.

Author contributions JH: design and conceptualized study; major role in the acquisition of data, analyzed the data; drafted the manuscript. MM: acquisition of data; revised the manuscript for intellectual content. CS: acquisition of data; revised the manuscript for intellectual content. ALH: analyzed the data; drafted the manuscript. EM: analyzed the data; revised the manuscript for intellectual content. BH: analyzed the data; revised the manuscript for intellectual content. RS: analyzed the data; revised the manuscript for intellectual content. TK: analyzed the data; revised the manuscript for intellectual content. MS: analyzed the data; revised the manuscript for intellectual content. TBE: design and conceptualized study; major role in the acquisition of data, analyzed the data; drafted the manuscript. SS: design and conceptualized study; major role in the acquisition of data, analyzed the data; drafted the manuscript.

Funding This study was supported by the Braun Stiftung, Melsungen, the Verum Stiftung, the Else Kröner Fresenius-Stiftung, and the Ara Parseghian Medical Research Fund (SAS). SAS was funded by the LMU Advanced Clinical Scientist Excellence Programme. JH is (partially) funded by the German Federal Ministry of Education and Research (Grant Numbers 01ZZ1603[A-D] and 01ZZ1804[A-H] (DIFUTURE)).

\section{Compliance with ethical standards}

Conflicts of interest JH reports a grant for OCT research from the Friedrich-Baur-Stiftung and Merck, personal fees and non-financial support from Merck, Alexion, Novartis, Roche, Santhera, Biogen, Heidelberg Engineering, Sanofi Genzyme and non-financial support of the Guthy-Jackson Charitable Foundation, all outside the submitted work. MS is Joint Chief Editor of the Journal of Neurology, Editor in Chief of Frontiers of Neurootology and Section Editor of F1000. He has received speaker's honoraria from Abbott, Actelion, Auris Medical, Biogen, Eisai, Grünenthal, GSK, Henning Pharma, Interacoustics, Merck, MSD, Otometrics, Pierre-Fabre, TEVA, UCB. He is a shareholder of IntraBio. He acts as a consultant for Abbott, Actelion, AurisMedical, Heel, IntraBio, and Sensorion. TBE received honoraria for lecturing from Actelion and Sanofi-Genzyme. SAS has received honoraria from Actelion Pharma. TK has received travel expenses and speaker honoraria from Bayer Vital, Teva Pharma, Merck, Novartis Pharma, SanofiAventis/Genzyme, CLS Behring, Roche Pharma and Biogen as well as grant support from Bayer-Schering AG, Novartis and Chugai Pharma. AL-H has received travel expenses from BioMarin. EM has received travel reimbursement from Sobi and Dr. Schär and was paid for advisory services from Sobi and Biomarin. All other authors (MM, CS, $\mathrm{BH}, \mathrm{RS}$, and SAS) have nothing to disclose and no conflicts of interest.

Ethics approval The study was performed in accordance with the Helsinki II Declaration and approved by the ethics committee of the Ludwig-Maximilians-University, Munich, Medical Faculty (part of project no 280-16).

Informed consent All participants (or their legal representatives) gave written informed consent.

Open Access This article is licensed under a Creative Commons Attribution 4.0 International License, which permits use, sharing, adaptation, distribution and reproduction in any medium or format, as long as you give appropriate credit to the original author(s) and the source, provide a link to the Creative Commons licence, and indicate if changes were made. The images or other third party material in this article are included in the article's Creative Commons licence, unless indicated otherwise in a credit line to the material. If material is not included in the article's Creative Commons licence and your intended use is not permitted by statutory regulation or exceeds the permitted use, you will need to obtain permission directly from the copyright holder. To view a copy of this licence, visit http://creativecommons.org/licenses/by/4.0/.

\section{References}

1. Vanier MT (2010) Niemann-Pick disease type C. Orphanet J Rare Dis 5:16

2. Geberhiwot T, Moro A, Dardis A, Ramaswami U, Sirrs S, Marfa MP, Vanier MT, Walterfang M, Bolton S, Dawson C, Heron B, Stampfer M, Imrie J, Hendriksz C, Gissen P, Crushell E, Coll MJ, Nadjar Y, Klunemann H, Mengel E, Hrebicek M, Jones SA, Ory D, Bembi B, Patterson M, International Niemann-Pick Disease R (2018) Consensus clinical management guidelines for NiemannPick disease type C. Orphanet J Rare Dis 13:50

3. Vanier MT, Millat G (2003) Niemann-Pick disease type C. Clin Genet 64:269-281

4. Palmer M, Green WR, Maumenee IH, Valle DL, Singer HS, Morton SJ, Moser HW (1985) Niemann-Pick disease-type C. Ocular histopathologic and electron microscopic studies. Arch Ophthalmol 103:817-822

5. te Vruchte D, Lloyd-Evans E, Veldman RJ, Neville DC, Dwek RA, Platt FM, van Blitterswijk WJ, Sillence DJ (2004) Accumulation of glycosphingolipids in Niemann-Pick C disease disrupts endosomal transport. J Biol Chem 279:26167-26175 
6. Lloyd-Evans E, Morgan AJ, He X, Smith DA, Elliot-Smith E, Sillence DJ, Churchill GC, Schuchman EH, Galione A, Platt FM (2008) Niemann-Pick disease type $\mathrm{C} 1$ is a sphingosine storage disease that causes deregulation of lysosomal calcium. Nat Med 14:1247-1255

7. Vance JE (2012) Dysregulation of cholesterol balance in the brain: contribution to neurodegenerative diseases. Dis Model Mech 5:746-755

8. Doria M, Maugest L, Moreau T, Lizard G, Vejux A (2016) Contribution of cholesterol and oxysterols to the pathophysiology of Parkinson's disease. Free Radic Biol Med 101:393-400

9. Paul R, Choudhury A, Borah A (2015) Cholesterol - A putative endogenous contributor towards Parkinson's disease. Neurochem Int 90:125-133

10. Nixon RA (2005) Endosome function and dysfunction in Alzheimer's disease and other neurodegenerative diseases. Neurobiol Aging 26:373-382

11. Yamazaki T, Chang TY, Haass C, Ihara Y (2001) Accumulation and aggregation of amyloid beta-protein in late endosomes of Niemann-pick type C cells. J Biol Chem 276:4454-4460

12. Erickson RP, Bernard O (2002) Studies on neuronal death in the mouse model of Niemann-Pick $\mathrm{C}$ disease. J Neurosci Res 68:738-744

13. Cupidi C, Frangipane F, Gallo M, Clodomiro A, Colao R, Bernardi L, Anfossi M, Conidi ME, Vasso F, Curcio SA, Mirabelli M, Smirne N, Torchia G, Muraca MG, Puccio G, Di Lorenzo R, Zampieri S, Romanello M, Dardis A, Maletta RG, Bruni AC (2017) Role of Niemann-Pick type C disease mutations in dementia. J Alzheimers Dis 55:1249-1259

14. Kirbas S, Turkyilmaz K, Anlar O, Tufekci A, Durmus M (2013) Retinal nerve fiber layer thickness in patients with Alzheimer disease. J Neuroophthalmol 33:58-61

15. Albrecht P, Muller AK, Sudmeyer M, Ferrea S, Ringelstein M, Cohn E, Aktas O, Dietlein T, Lappas A, Foerster A, Hartung HP, Schnitzler A, Methner A (2012) Optical coherence tomography in parkinsonian syndromes. PLoS ONE 7:e34891

16. Lo SM, McNamara J, Seashore MR, Mistry PK (2010) Misdiagnosis of Niemann-Pick disease type $\mathrm{C}$ as Gaucher disease. $\mathrm{J}$ Inherit Metab Dis 33(Suppl 3):S429-433

17. McNeill A, Roberti G, Lascaratos G, Hughes D, Mehta A, Garway-Heath DF, Schapira AH (2013) Retinal thinning in Gaucher disease patients and carriers: results of a pilot study. Mol Genet Metab 109:221-223

18. Schippling S, Balk LJ, Costello F, Albrecht P, Balcer L, Calabresi PA, Frederiksen JL, Frohman E, Green AJ, Klistorner A, Outteryck O, Paul F, Plant GT, Traber G, Vermersch P, Villoslada P, Wolf S, Petzold A (2015) Quality control for retinal OCT in multiple sclerosis: validation of the OSCAR-IB criteria. MSJ 21:163-170

19. Cruz-Herranz A, Balk LJ, Oberwahrenbrock T, Saidha S, Martinez-Lapiscina EH, Lagreze WA, Schuman JS, Villoslada P, Calabresi P, Balcer L, Petzold A, Green AJ, Paul F, Brandt AU, Albrecht P (2016) The APOSTEL recommendations for reporting quantitative optical coherence tomography studies. Neurology 86:2303-2309

20. Bremova-Ertl T, Bardins S, Abel L, Walterfang M, Amraoui Y, Mengel E, Tavasoli A, Reza Ashrafi M, Salsano E, Malinova V, Kolnikova M, Dinopoulos A, Torres Martin J, Insua J, Kolb S, Brecht A, Strupp M Defining ocular motor biomarkers in Niemann-Pick disease type C: results from a systematic multi-continental study in 72 patients, under revision.

21. Schneider E, Villgrattner T, Vockeroth J, Bartl K, Kohlbecher S, Bardins S, Ulbrich H, Brandt T (2009) EyeSeeCam: an eye movement-driven head camera for the examination of natural visual exploration. Ann N Y Acad Sci 1164:461-467
22. Pineda M, Perez-Poyato MS, O'Callaghan M, Vilaseca MA, Pocovi M, Domingo R, Portal LR, Perez AV, Temudo T, Gaspar A, Penas JJ, Roldan S, Fumero LM, de la Barca OB, Silva MT, Macias-Vidal J, Coll MJ (2010) Clinical experience with miglustat therapy in pediatric patients with Niemann-Pick disease type C: a case series. Mol Genet Metab 99:358-366

23. Iturriaga $\mathrm{C}$, Pineda M, Fernandez-Valero EM, Vanier MT, Coll MJ (2006) Niemann-Pick C disease in Spain: clinical spectrum and development of a disability scale. J Neurol Sci 249:1-6

24. Schmitz-Hubsch T, du Montcel ST, Baliko L, Berciano J, Boesch S, Depondt C, Giunti P, Globas C, Infante J, Kang JS, Kremer B, Mariotti C, Melegh B, Pandolfo M, Rakowicz M, Ribai P, Rola R, Schols L, Szymanski S, van de Warrenburg BP, Durr A, Klockgether T, Fancellu R (2006) Scale for the assessment and rating of ataxia: development of a new clinical scale. Neurology 66:1717-1720

25. Schmitz-Hubsch T, Giunti P, Stephenson DA, Globas C, Baliko L, Sacca F, Mariotti C, Rakowicz M, Szymanski S, Infante J, van de Warrenburg BP, Timmann D, Fancellu R, Rola R, Depondt C, Schols L, Zdzienicka E, Kang JS, Dohlinger S, Kremer B, Melegh B, Filla A, Klockgether T (2008) SCA Functional Index: a useful compound performance measure for spinocerebellar ataxia. Neurology 71:486-492

26. Bremova-Ertl T, Sztatecsny C, Brendel M, Moser M, Möller B, Clevert D, Rominger A, Ninov D, Strupp M, Schneider SA (2020) The clinical, ocular motor and imaging profile of niemann pick type $\mathrm{C}$ heterozygosity. Neurology (in press)

27. Loh EH, Ong YT, Venketasubramanian N, Hilal S, Thet N, Wong TY, Chen CPL, Cheung CY (2017) Repeatability and reproducibility of retinal neuronal and axonal measures on spectral-domain optical coherence tomography in patients with cognitive impairment. Front Neurol 8:359

28. Aktas O, Hartung HP (2019) CSI: Multiple sclerosis. Tracing optic nerve involvement by standardized optical coherence tomography. Ann Neurol 85:615-617

29. Conger D, Beh SC (2019) Seeing function in structure: "incidental" eye findings on OCT in a patient with multiple sclerosis. Mult Scler Relat Disord 31:72-73

30. London F, Zephir H, Drumez E, Labreuche J, Hadhoum N, Lannoy J, Hodel J, Vermersch P, Pruvo JP, Leclerc X, Outteryck O (2019) Optical coherence tomography: a window to the optic nerve in clinically isolated syndrome. Brain 142:903-915

31. Cheung CY, Ikram MK, Chen C, Wong TY (2017) Imaging retina to study dementia and stroke. Prog Retin Eye Res 57:89-107

32. Mutlu U, Colijn JM, Ikram MA, Bonnemaijer PWM, Licher S, Wolters FJ, Tiemeier H, Koudstaal PJ, Klaver CCW, Ikram MK (2018) Association of retinal neurodegeneration on optical coherence tomography with dementia: a population-based study. JAMA Neurol 75:1256-1263

33. Sari ES, Koc R, Yazici A, Sahin G, Ermis SS (2015) Ganglion cell-inner plexiform layer thickness in patients with Parkinson disease and association with disease severity and duration. J Neuroophthalmol 35:117-121

34. Ferrari L, Huang SC, Magnani G, Ambrosi A, Comi G, Leocani L (2017) Optical coherence tomography reveals retinal neuroaxonal thinning in frontotemporal dementia as in Alzheimer's disease. J Alzheimers Dis 56:1101-1107

35. Marziani E, Pomati S, Ramolfo P, Cigada M, Giani A, Mariani C, Staurenghi G (2013) Evaluation of retinal nerve fiber layer and ganglion cell layer thickness in Alzheimer's disease using spectral-domain optical coherence tomography. Invest Ophthalmol Vis Sci 54:5953-5958

36. Carelli V, Ross-Cisneros FN, Sadun AA (2002) Optic nerve degeneration and mitochondrial dysfunction: genetic and acquired optic neuropathies. Neurochem Int 40:573-584 
37. Fortuna F, Barboni P, Liguori R, Valentino ML, Savini G, Gellera C, Mariotti C, Rizzo G, Tonon C, Manners D, Lodi R, Sadun AA, Carelli V (2009) Visual system involvement in patients with Friedreich's ataxia. Brain 132:116-123

38. Pula JH, Towle VL, Staszak VM, Cao D, Bernard JT, Gomez CM (2011) Retinal nerve fibre layer and macular thinning in spinocerebellar ataxia and cerebellar multisystem atrophy. Neuroophthalmology 35:108-114

39. Cheung CY, Ong YT, Hilal S, Ikram MK, Low S, Ong YL, Venketasubramanian N, Yap P, Seow D, Chen CL, Wong TY (2015) Retinal ganglion cell analysis using high-definition optical coherence tomography in patients with mild cognitive impairment and Alzheimer's disease. J Alzheimers Dis 45:45-56

40. Yu JG, Feng YF, Xiang Y, Huang JH, Savini G, Parisi V, Yang WJ, Fu XA (2014) Retinal nerve fiber layer thickness changes in Parkinson disease: a meta-analysis. PLoS ONE 9:e85718

41. Vazquez MC, Balboa E, Alvarez AR, Zanlungo S (2012) Oxidative stress: a pathogenic mechanism for Niemann-Pick type C disease. Oxid Med Cell Longev 2012:205713

42. Claudepierre T, Paques M, Simonutti M, Buard I, Sahel J, Maue RA, Picaud S, Pfrieger FW (2010) Lack of Niemann-Pick type $\mathrm{C} 1$ induces age-related degeneration in the mouse retina. Mol Cell Neurosci 43:164-176
43. Platt N, Speak AO, Colaco A, Gray J, Smith DA, Williams IM, Wallom KL, Platt FM (2016) Immune dysfunction in NiemannPick disease type C. J Neurochem 136(Suppl 1):74-80

44. Petzold A, Balcer LJ, Calabresi PA, Costello F, Frohman TC, Frohman EM, Martinez-Lapiscina EH, Green AJ, Kardon R, Outteryck O, Paul F, Schippling S, Vermersch P, Villoslada P, Balk LJ, Ern-Eye I (2017) Retinal layer segmentation in multiple sclerosis: a systematic review and meta-analysis. Lancet Neurol 16:797-812

45. Mata IF, Shi M, Agarwal P, Chung KA, Edwards KL, Factor SA, Galasko DR, Ginghina C, Griffith A, Higgins DS, Kay DM, Kim H, Leverenz JB, Quinn JF, Roberts JW, Samii A, Snapinn KW, Tsuang DW, Yearout D, Zhang J, Payami H, Zabetian CP (2010) SNCA variant associated with Parkinson disease and plasma alpha-synuclein level. Arch Neurol 67:1350-1356

46. Yan X, Ma L, Hovakimyan M, Lukas J, Wree A, Frank M, Guthoff R, Rolfs A, Witt M, Luo J (2014) Defects in the retina of Niemann-pick type C 1 mutant mice. BMC Neurosci 15:126

47. Chen H, Chan AY, Stone DU, Mandal NA (2014) Beyond the cherry-red spot: Ocular manifestations of sphingolipid-mediated neurodegenerative and inflammatory disorders. Surv Ophthalmol 59:64-76

\section{Affiliations}

\section{Joachim Havla ${ }^{1}$ - Marlene Moser ${ }^{2}$ - Clara Sztatecsny ${ }^{2}$ - Amelie S. Lotz-Havla ${ }^{3}$ - Esther M. Maier ${ }^{3} \cdot$ Baccara Hizli $^{2}$. Regina Schinner ${ }^{5} \cdot$ Tania Kümpfel $^{1} \cdot$ Michael Strupp $^{2} \cdot$ Tatiana Bremova-Ert| $^{2,4} \cdot$ Susanne A. Schneider ${ }^{2}$}

\author{
Marlene Moser \\ marlene_moser@yahoo.de \\ Clara Sztatecsny \\ clara.sztatecsny@gmail.com \\ Amelie S. Lotz-Havla \\ amelie.lotz@med.uni-muenchen \\ Esther M. Maier \\ esther.maier@med.uni-muenchen.de \\ Baccara Hizli \\ baccara.hizli@campus.lmu.de \\ Regina Schinner \\ regina.schinner@med.uni-muenchen.de \\ Tania Kümpfel \\ tania.kuempfel@med.uni-muenchen.de \\ Michael Strupp \\ michael.strupp@med.uni-muenchen.de
}

Tatiana Bremova-Ertl

Tatiana.Bremova-Ertl@insel.ch

1 Institute of Clinical Neuroimmunology, LudwigMaximilians University, Marchioninistr. 15, 81377 Munich, Germany

2 Department of Neurology, Ludwig-Maximilians University München, Marchioninistr. 15, 81377 Munich, Germany

3 Dr. von Hauner Children's Hospital, Ludwig-Maximilians University, Munich, Germany

4 Department of Neurology, University Hospital Bern, Inselspital, University of Bern, Bern, Switzerland

5 Institute of Clinical Radiology, Ludwig-Maximilians University, Marchioninistr. 15, Munich 81377, Germany 